\title{
Efeitos imediatos do alongamento em diferentes posicionamentos
}

\author{
Instant effects of stretching in different positions
}

\author{
Igor de Matos Pinheiro $^{[a]}$, Ana Lúcia Barbosa Góes ${ }^{[b]}$
}

[a] Fisioterapeuta das Obras Sociais Irmã Dulce, graduado em Fisioterapia pela Escola Bahiana de Medicina e Saúde Pública, Salvador, BA - Brasil, e-mail: igordematospinheiro@gmail.com

[b] Fisioterapeuta Especialista em Correção da Postura, professora assistente do curso de Fisioterapia da Escola Bahiana de Medicina e Saúde Pública, Salvador, BA - Brasil, e-mail: albgoes@bahiana.edu.br

\section{Resumo}

Introdução: Exercícios de alongamento aumentam a extensibilidade dos tecidos moles e restauram o comprimento muscular. O alongamento produz efeitos imediatos e uma única sessão é capaz de melhorar a extensibilidade muscular e mobilidade articular. A técnica de alongamento e o posicionamento influenciam no nível de tensão muscular. Objetivo: O objetivo geral deste estudo foi determinar os efeitos imediatos do alongamento na flexibilidade do músculo iliopsoas em diferentes posicionamentos, em uma única sessão, identificando máxima tensão desta musculatura e relacionando o alongamento com alterações comuns do alinhamento lombo-pélvico no plano sagital. Metodologia: Trata-se de um ensaio clínico controlado randomizado unicego. A população compreendeu estudantes com encurtamento do músculo iliopsoas. Foi realizada uma sessão de alongamento estático por um minuto com a extensão da articulação do quadril nos posicionamentos decúbito dorsal, semiflexão de joelhos, decúbito ventral e decúbito lateral. Para análise pareada das posições para o alongamento, foi utilizado o teste Wilcoxon $(\alpha \leq 0,01)$. Resultados: Participaram do estudo 40 estudantes, divididos em grupos compostos por dez indivíduos. A média da idade foi de $22 \pm 1,7$ anos. A maioria dos participantes era do sexo feminino $(77,5 \%)$ e $75 \%$ relataram episódio de dor lombar em alguma fase da vida. Observou-se, como efeitos imediatos do alongamento, um ganho na flexibilidade muscular nos posicionamentos decúbito dorsal, semiflexão de joelhos e decúbito lateral. Observou-se também tendência à retroversão e neutralização da pelve. Conclusão: Os diferentes posicionamentos fornecem maior variabilidade de posições, permitindo ao fisioterapeuta escolher qual a mais adequada para cada indivíduo.

Palavras-chave: Exercícios de alongamento muscular. Músculo psoas. Coluna vertebral. 


\begin{abstract}
Introduction: Stretching exercises increase the extensibility of soft tissue and restore muscle length. Stretching produces immediate effects and a single session is able to improve the extensibility and muscle mobility. The technique of stretching and positioning affect the level of muscle tension. Objective: The aim of this study was to determine the immediate effects of stretching on flexibility of the iliopsoas muscle in different positions through a single session, identifying maximum tension of muscles and connecting the stretch with common changes of lumbar-pelvic alignment in the sagittal plane. Methodology: It was a controlled clinical assay randomized single blind. The population was composed by students with shortening of the iliopsoas muscle. Was performed a static stretching session for a minute by extending the hip joint in supine positions, semi-flexion of knees, prone and lateral position. For paired analysis of the positions for the stretch was used Wilcoxon test $(\alpha \leq 0,01)$. Results: Participants were 40 students, divided in groups of ten individuals each. The average age was $22 \pm 1.7$ years. Most participants were female $(77.5 \%)$ and $75 \%$ reported an episode of low back pain at some stage of life. It was observed, as the immediate effects of stretching, a gain in muscle flexibility in the supine position, semi-flexion of knees and lateral position. There was also a tendency to retroversion of the pelvis and neutralization. Conclusion: The different positions provide a greater range of positions allowing the physiotherapist to choose which is most suitable for each individual.
\end{abstract}

Keywords: Muscle stretching exercises. Psoas muscle. Spine.

\title{
Introdução
}

O movimento do homem representa sua forma de expressão, seu modo de interação com o mundo e envolve fatores mecânicos, neurológicos, biológicos e psicológicos (1). A produção e o controle dos movimentos são realizados pelos músculos por meio da sua contração e relaxamento, em associação com o sistema nervoso (2).

Em todo o mundo, cerca de $80 \%$ das pessoas apresentarão dores na região lombar em alguma fase da vida (3). A flexibilidade limitada do quadril e da coluna lombar pode predispor os indivíduos ao desenvolvimento da lombalgia, um problema que gera incapacidade, sendo a principal causa de afastamentos no trabalho (3). Os custos médicos diretos e indiretos com o tratamento desta patologia estão entre 50 a 100 bilhões de dólares ao ano (4).

Um dos músculos envolvidos na disfunção do movimento da coluna lombar é o iliopsoas (5). Este músculo, por meio de sua ação sinergista, promove estabilização deste segmento, sendo responsável pela manutenção da postura (5-9). Disfunção do movimento pode provocar desequilíbrios musculares, quando os músculos permanecem constantemente encurtados ou alongados um em relação ao outro (2). Alterações no comprimento do músculo iliopsoas (tamanho longitudinal do músculo) podem comprometer o bom funcionamento do corpo humano e resultar no aparecimento de diversas patologias, como hiperlordose lombar, constipação intestinal e insuficiência renal (5).

Os exercícios de alongamento aumentam a extensibilidade dos tecidos moles e restauram o comprimento muscular por afetar as propriedades contráteis da fibra muscular e pelas alterações viscoelásticas promovidas na unidade músculo-tendão (10-17). O alongamento produz efeitos imediatos e uma única sessão em indivíduos saudáveis é capaz de melhorar a flexibilidade muscular (amplitude máxima passiva fisiológica) e a mobilidade articular (10).

Várias técnicas de alongamento podem ser usadas, algumas sendo mais efetivas que outras (15). O alongamento pode variar quanto à técnica, tais como alongamento balístico, estático (sustentado), FNP (Facilitação Neuromuscular Proprioceptiva), entre outros; e quanto ao posicionamento do indivíduo (sentado, ortostase, decúbitos) $(11,18,19)$.

O alongamento estático é de fácil aplicação, devendo ser realizado de acordo com os princípios biomecânicos de alongamento - afastamento das inserções musculares no mesmo sentido da fibra muscular (17, 20, 21). O tempo de sustentação do alongamento estático de 60 segundos promove modificações na unidade 
músculo-tendão, alterando o número de sarcômeros em série $(13,14,18,22,23)$. Tanto o alongamento estático passivo quanto o ativo são eficazes no aumento da flexibilidade dos músculos flexores do quadril (11).

A escolha do melhor posicionamento pode determinar o momento no qual ocorra máxima tensão na musculatura. O alongamento eficaz, que realize a máxima tensão muscular, irá restaurar o comprimento muscular e restabelecer a biomecânica normal do indivíduo (20). Espera-se, com isso, favorecer o bem-estar, reduzindo a incidência de patologias e suas repercussões em nível econômico, social e de qualidade de vida $(11,22)$.

O alongamento do iliopsoas é realizado com extensão da articulação do quadril, promovendo afastamento das inserções musculares (20). Diversos posicionamentos vêm sendo realizados na prática fisioterapêutica e ainda não está muito claro se todas as posições são eficazes e qual promove maior ganho de flexibilidade muscular.

O objetivo geral deste estudo foi determinar os efeitos imediatos do alongamento na flexibilidade do músculo iliopsoas em diferentes posicionamentos, em uma única sessão, identificando a máxima tensão desta musculatura e relacionando o alongamento com as alterações comuns do alinhamento lombo-pélvico no plano sagital.

\section{Metodologia}

Este trabalho foi um ensaio clínico controlado, randomizado e unicego. A população do estudo compreendeu estudantes, sendo a coleta de dados realizada por um fisioterapeuta devidamente treinado e sem conhecimento prévio do objetivo do estudo, no período de novembro de 2006 a abril de 2007. O tamanho amostral foi calculado no programa BioEstat ${ }^{\circledR} 4.0$ por meio do teste ANOVA (poder do teste $95 \%$ e alfa de 0,05$)$, a partir de dados do plano piloto, sendo encontrado um número de 40 estudantes. O plano piloto também foi realizado para calibração dos instrumentos de coleta e para adequação das perguntas do questionário de triagem. Optou-se pela realização dos procedimentos apenas no músculo iliopsoas esquerdo, como forma de padronização. Os responsáveis pela pesquisa receberam os estudantes voluntários em local, dia e hora marcados.

A amostra foi composta por estudantes que apresentaram encurtamento do músculo iliopsoas confirmado pelo teste de Thomas (24). Foram excluídos da pesquisa os estudantes com dor no momento da entrevista em membros inferiores, coluna lombar ou quadril, uso de medicamentos sedativos ou analgésicos, ou indivíduos que estavam realizando tratamento fisioterapêutico.

Este trabalho foi aprovado pelo Comitê de Ética em Pesquisa em novembro de 2006, respeitando os aspectos éticos, de confidencialidade e afirmando a ausência de riscos aos participantes, em concordância com o Conselho Nacional de Saúde (Resolução 196/96).

Os estudantes assinaram o termo de consentimento livre e esclarecido, e compareceram a um espaço físico adequado com roupa apropriada para avaliação (top e short para mulheres e short para homens). O trabalho foi desenvolvido em um laboratório na própria instituição, o qual possui os materiais necessários como maca, goniômetro, marcadores corporais esféricos (bolas de isopor), e espaço suficiente para realização dos procedimentos.

O trabalho foi realizado em oito etapas:

1) Aplicação de um questionário específico de triagem, a partir do qual foram obtidas informações sobre idade, peso, altura, realização de tratamento fisioterapêutico, presença de dor no momento da entrevista, episódio de dor lombar e uso de alguma medicação.

2) Realização do teste de Thomas para devida confirmação de encurtamento do músculo iliopsoas. No teste, o indivíduo posicionou-se em decúbito dorsal sobre uma maca, com a pelve em posição neutra e com os joelhos na borda da maca. O examinador flexionou ambos os joelhos na direção do tórax do paciente, permitindo que a coluna lombar ficasse plana em relação à superfície, proporcionando um correto alinhamento da pelve. A perna que estava sendo testada 
foi abaixada em direção à maca enquanto o indivíduo mantinha a outra perna em flexão máxima. Considerou-se encurtamento do músculo iliopsoas qualquer angulação observada entre a maca e o membro que estava sendo avaliado (24).

3) Marcação dos pontos anatômicos com marcadores corporais esféricos (bolas de isopor) recobertos com película com capacidade de refletir a luz do flash, nos seguintes pontos: espinha ilíaca ântero-superior esquerda e espinha ilíaca póstero-inferior esquerda - três dedos do indivíduo abaixo da espinha ilíaca póstero-superior esquerda (25).

4) Fotografia digitalizada do indivíduo com a câmera fotográfica Kodak EasyShare ${ }^{\circledR}$ C300 3.2 megapixels, em vista lateral esquerda, a uma distância de $3 \mathrm{~m}$ delimitados por marcadores no chão. A câmera foi posicionada tomando-se como base metade da altura do indivíduo a ser analisado (26). A fotografia foi posteriormente analisada no Software para Avaliação Postural - SAPO ${ }^{\circledR}$ versão 0.63 da Universidade do Estado de São Paulo (USP). Para maior fidedignidade, a calibração das imagens foi realizada de acordo com o programa. A fotografia teve finalidade de analisar o alinhamento pélvico no plano sagital a partir da comparação entre o posicionamento da espinha ilíaca ântero-superior em relação à espinha ilíaca póstero-inferior. Quando os dois pontos anatômicos encontram-se na mesma horizontal, a pelve está equilibrada no plano sagital. Quando o indicador anterior está mais baixo que o posterior, é sinal de anteversão pélvica, e quando o indicador anterior está mais alto que o posterior, é sinal de retroversão pélvica (25). O alinhamento pélvico no plano sagital foi uma variável dependente deste estudo. Antes da tomada da fotografia, foi solicitada ao indivíduo a realização de uma inspiração profunda em três tempos (atingindo a máxima capacidade inspiratória) como forma de padronização das fotos.

5) Mensuração, por outro examinador devidamente treinado, do ângulo articular do quadril que represente o grau de encurtamento muscular do músculo iliopsoas por meio do teste de Thomas (24). Para a realização deste, foi utilizado um goniômetro universal de plástico da marca CARCI ${ }^{\circledR}$ que foi alinhado nos seguintes acidentes ósseos: eixo do goniômetro foi colocado no trocanter maior do fêmur, o braço fixo ao longo da linha média lateral do fêmur na direção do epicôndilo lateral e o braço móvel acompanhando a face lateral da diáfise do fêmur $(2,24)$. Foi utilizada uma fita adesiva ao longo da linha média lateral do fêmur até o epicôndilo lateral, para melhor alinhamento goniométrico, e foram realizadas três mensurações para maior confiabilidade da medida, sendo retirada a média entre elas (24). Esta é a variável dependente. Antes da mensuração, foi realizada uma tração sacral pelo examinador, como forma de estabilização da coluna lombar e melhor análise do grau de encurtamento muscular.

6) Realização de quatro versões do alongamento baseados no teste de Thomas - extensão da articulação coxofemural -, que é a variável independente (2). Os alongamentos foram dispostos em sequência mediante sorteio: decúbito dorsal (DD), semiflexão de joelhos (SF), decúbito ventral (DV) e decúbito lateral (DL). O posicionamento e o movimento são descritos a seguir (Figura 1).

a) Indivíduo em decúbito dorsal, na extremidade da maca, examinador flexiona ambos os joelhos em direção ao tórax. O membro que está sendo testado é colocado para baixo enquanto que o examinador, com a mão no joelho, mantém o quadril e o joelho do outro membro em flexão máxima junto ao tórax. O examinador empurra o joelho do membro testado para baixo para a realização do alongamento dos flexores de quadril $(27,28)$.

b) Indivíduo com um dos joelhos no chão em extensão da articulação coxofemural, posicionando o membro inferior o mais longe possível do corpo. O outro pé será mantido no chão. O indivíduo realiza uma flexão de tronco buscando maior extensão da articulação coxofemural e consequente alongamento dos flexores de quadril $(27,29)$.

c) Indivíduo em decúbito ventral, examinador realiza extensão da articulação coxofemural com uma mão em joelho. Aplica-se uma pressão firme, com a outra mão, ao nível da região posterior do ilíaco, estabilizando a pelve. O joelho do indivíduo deve ser mantido em $90^{\circ}$ de flexão, inibindo uma insuficiência passiva do reto femural (7). 
d) Indivíduo em decúbito lateral para o lado contralateral ao músculo que será alongado. O examinador realiza extensão da articulação coxofemural com uma mão nos joelhos e antebraço na perna. A outra mão aplica uma pressão firme, estabilizando, assim, a pelve ao nível da região posterior do ilíaco (7). Imediatamente após a realização do alongamento foi obtida uma nova mensuração do ângulo articular do quadril por meio do teste de Thomas, para posterior análise estatística, sendo realizado da mesma forma e pelo mesmo examinador da primeira coleta (24). A alteração de comprimento do músculo iliopsoas foi a variável dependente.
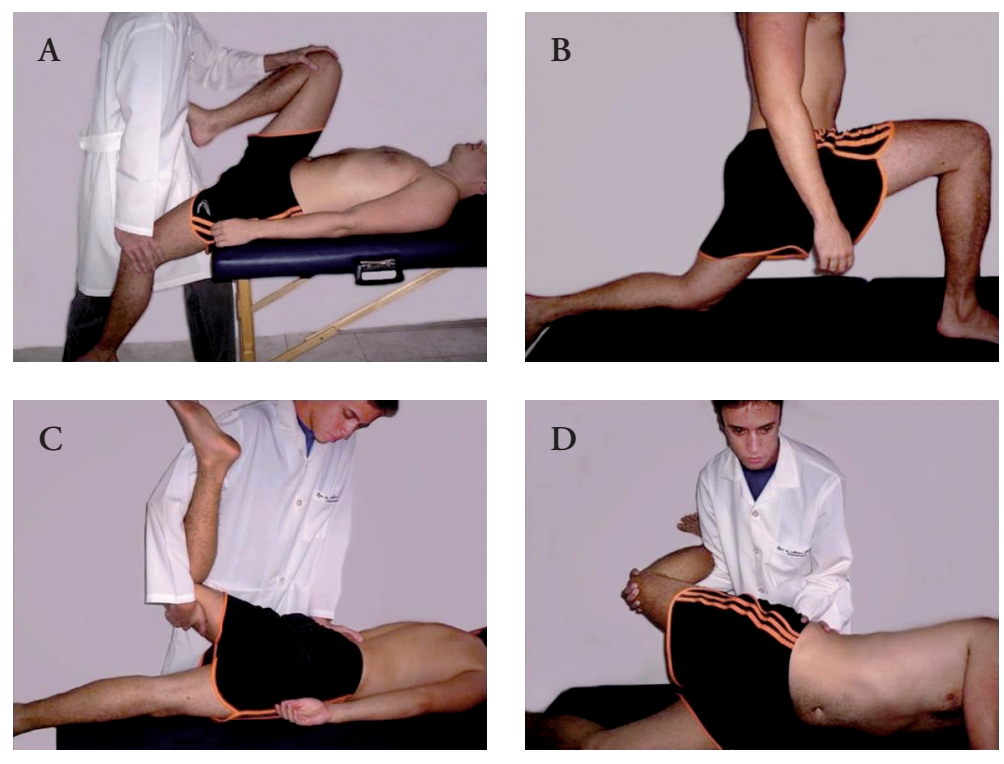

Figura 1 - Posições para alongamento: A = decúbito dorsal; B = semiflexão de joelhos. $\mathrm{C}=$ decúbito ventral; $\mathrm{D}=$ decúbito lateral esquerdo

7) Marcação dos mesmos pontos anatômicos citados na etapa 3.

8) Tomada de uma nova fotografia na mesma posição. A alteração no alinhamento pélvico no plano sagital também foi variável dependente deste estudo.

Os alunos foram distribuídos entre quatro grupos, de acordo com a ordem de chegada (aparição), ou seja, o primeiro aluno no grupo DD, o segundo aluno no grupo SF, o terceiro aluno no grupo DV, o quarto aluno no grupo DL, e assim sucessivamente. $\mathrm{O}$ alongamento foi realizado apenas uma vez e mantido durante um minuto de forma sustentada (estática) (28). A intensidade do alongamento foi aquela na qual o paciente conseguia suportar a mialgia inerente em qualquer alongamento.

As variáveis dependentes deste estudo foram a amplitude de movimento da articulação do quadril, observada com o ganho de comprimento muscular do músculo iliopsoas, e o alinhamento pélvico esquerdo (anteversão, retroversão e neutro). As variáveis independentes foram as posições para o alongamento (DD, SF, DV, DL). Foi utilizado o software BioEstat ${ }^{\circledR} 4.0$ para validação e correlação dos dados. A análise dos dados foi realizada por outro profissional sem qualquer relação com a coleta dos dados.

Para análise das variáveis dependentes foram calculadas a medida de tendência central (média aritmética) e a medida de dispersão (desvio padrão).

Para análise pareada das posições para o alongamento (DD, SF, DV, DL) foi utilizado o teste Wilcoxon. Foi realizada uma correção do valor alfa, sendo considerada significância com erro de 0,01 para todos os testes. 


\section{Resultados}

Compareceram ao local da pesquisa 41 estudantes, porém um indivíduo não participou por não apresentar encurtamento do músculo iliopsoas. Quarenta estudantes participaram do estudo e foram distribuídos nos quatro grupos, sendo cada grupo composto por dez indivíduos. A média da idade foi de $22 \pm 1,7$ anos. A maioria dos participantes era do sexo feminino $(77,5 \%)$. Trinta estudantes $(75 \%)$ relataram já ter apresentado algum episódio de dor lombar em alguma fase da vida.

A média da amplitude articular antes do alongamento no posicionamento decúbito dorsal foi de $2,66^{\circ} \pm 1,98^{\circ}$. Após a realização do alongamento foi observada uma média de $1,79^{\circ} \pm 1,44^{\circ}$ neste posicionamento (Tabela 1).

Tabela 1 - Análise da amplitude articular no posicionamento decúbito dorsal $*_{\mathrm{p}}=0,0077$

\begin{tabular}{llll}
\hline Indivíduo & $\begin{array}{c}\text { Amplitude antes } \\
\text { do alongamento }\end{array}$ & $\begin{array}{c}\text { Amplitude após } \\
\text { o alongamento }\end{array}$ & $\begin{array}{c}\text { Ganho de } \\
\text { amplitude articular }\end{array}$ \\
\hline 1 & $1^{\circ}$ & $0.16^{\circ}$ & $0.84^{\circ}$ \\
5 & $0.33^{\circ}$ & $0.16^{\circ}$ & $0.17^{\circ}$ \\
9 & $3^{\circ}$ & $2.33^{\circ}$ & $0.67^{\circ}$ \\
13 & $1^{\circ}$ & $0.83^{\circ}$ & $0.17^{\circ}$ \\
17 & $2.66^{\circ}$ & $0.66^{\circ}$ & $2^{\circ}$ \\
21 & $3.66^{\circ}$ & $3^{\circ}$ & $0.66^{\circ}$ \\
25 & $5.33^{\circ}$ & $3.66^{\circ}$ & $1.67^{\circ}$ \\
29 & $2.33^{\circ}$ & $2.33^{\circ}$ & $0^{\circ}$ \\
33 & $1^{\circ}$ & $0.83^{\circ}$ & 0.17 \\
37 & $6.33^{\circ}$ & $4^{\circ}$ & $2.33^{\circ}$ \\
\hline
\end{tabular}

No posicionamento semiflexão de joelhos, foi encontrada uma média da amplitude articular antes do alongamento de $2,49^{\circ} \pm 1,27^{\circ}$ e, após o alongamento, de $1,49^{\circ} \pm 0,96^{\circ}$ (Tabela 2).

Tabela 2 - Análise da amplitude articular no posicionamento semiflexão de joelhos

$$
*_{\mathrm{p}}=0,0077
$$

(Continua)

\begin{tabular}{lccc}
\hline Indivíduo & $\begin{array}{c}\text { Amplitude antes } \\
\text { do alongamento }\end{array}$ & $\begin{array}{c}\text { Amplitude após } \\
\text { o alongamento }\end{array}$ & $\begin{array}{c}\text { Ganho de } \\
\text { amplitude articular }\end{array}$ \\
\hline 2 & $5^{\circ}$ & $2.66^{\circ}$ & $2.34^{\circ}$ \\
6 & $3^{\circ}$ & $0.66^{\circ}$ & $2.34^{\circ}$ \\
10 & $0.33^{\circ}$ & $0.16^{\circ}$ & $0.17^{\circ}$ \\
14 & $1.66^{\circ}$ & $0.83^{\circ}$ & $0.83^{\circ}$ \\
\hline
\end{tabular}


Tabela 2 - Análise da amplitude articular no posicionamento semiflexão de joelhos

$$
*_{p}=0,0077
$$

(Conclusão)

\begin{tabular}{llcl}
\hline Indivíduo & $\begin{array}{c}\text { Amplitude antes } \\
\text { do alongamento }\end{array}$ & $\begin{array}{c}\text { Amplitude após } \\
\text { o alongamento }\end{array}$ & $\begin{array}{c}\text { Ganho de } \\
\text { amplitude articular }\end{array}$ \\
\hline 18 & $2.66^{\circ}$ & $1^{\circ}$ & $1.66^{\circ}$ \\
22 & $2^{\circ}$ & $1.66^{\circ}$ & $0.34^{\circ}$ \\
26 & $2.66^{\circ}$ & $1.33^{\circ}$ & $1.33^{\circ}$ \\
30 & $1.33^{\circ}$ & $1^{\circ}$ & $0.33^{\circ}$ \\
34 & $3^{\circ}$ & $3^{\circ}$ & $0^{\circ}$ \\
38 & $3.33^{\circ}$ & $2.66^{\circ}$ & $0.67^{\circ}$ \\
\hline
\end{tabular}

A média da amplitude articular foi de $2,68^{\circ} \pm 1,31^{\circ}$ antes da realização do alongamento na posição decúbito ventral. Depois do alongamento, foi encontrada uma média de $1,83^{\circ} \pm 1,22^{\circ}$ (Tabela 3 ).

Tabela 3 - Análise da amplitude articular no posicionamento decúbito ventral $*_{\mathrm{p}}=0,0117$

\begin{tabular}{llll}
\hline Indivíduo & $\begin{array}{c}\text { Amplitude antes } \\
\text { do alongamento }\end{array}$ & $\begin{array}{c}\text { Amplitude após } \\
\text { o alongamento }\end{array}$ & $\begin{array}{c}\text { Ganho de } \\
\text { amplitude articular }\end{array}$ \\
\hline 3 & $4^{\circ}$ & $3^{\circ}$ & $1^{\circ}$ \\
7 & $2.83^{\circ}$ & $2.83^{\circ}$ & $0^{\circ}$ \\
11 & $2.66^{\circ}$ & $2^{\circ}$ & $0.66^{\circ}$ \\
15 & $3^{\circ}$ & $1^{\circ}$ & $2^{\circ}$ \\
19 & $3^{\circ}$ & $1.66^{\circ}$ & $1.34^{\circ}$ \\
23 & $0.66^{\circ}$ & $0.33^{\circ}$ & $0.33^{\circ}$ \\
27 & $2.33^{\circ}$ & $2.33^{\circ}$ & $0^{\circ}$ \\
31 & $0.66^{\circ}$ & $0.33^{\circ}$ & $0.33^{\circ}$ \\
35 & $2.66^{\circ}$ & $0.83^{\circ}$ & $1.83^{\circ}$ \\
39 & $5^{\circ}$ & $4^{\circ}$ & $1^{\circ}$ \\
\hline
\end{tabular}

No posicionamento decúbito lateral esquerdo, foi encontrada uma média da amplitude articular de $2,94^{\circ} \pm 3,13^{\circ}$ antes do alongamento e, após sua realização, uma média de $1,59^{\circ} \pm 2,01^{\circ}$ (Tabela 4).

Em relação ao alinhamento pélvico no plano sagital, 55\% dos indivíduos apresentaram retroversão da hemipelve esquerda, não sendo encontrada qualquer pelve neutra antes do alongamento. Houve tendência à retroversão e neutralização após realização do alongamento em todos os grupos. Três indivíduos não seguiram este padrão de alinhamento, sendo observadas as seguintes alterações: dois indivíduos aumentaram a anteversão (posicionamentos decúbito dorsal e decúbito ventral) e um manteve o mesmo alinhamento pélvico após a realização do alongamento (posicionamento decúbito lateral esquerdo). 
Tabela 4 - Análise da amplitude articular no posicionamento decúbito lateral ${ }_{\mathrm{p}}=0,0077$

\begin{tabular}{lccl}
\hline Indivíduo & $\begin{array}{c}\text { Amplitude antes } \\
\text { do alongamento }\end{array}$ & $\begin{array}{c}\text { Amplitude após } \\
\text { o alongamento }\end{array}$ & $\begin{array}{c}\text { Ganho de } \\
\text { amplitude articular }\end{array}$ \\
\hline 4 & $2^{\circ}$ & $0.66^{\circ}$ & $1.34^{\circ}$ \\
8 & $11.5^{\circ}$ & $7^{\circ}$ & $4.5^{\circ}$ \\
12 & $0.66^{\circ}$ & $0.66^{\circ}$ & $0^{\circ}$ \\
16 & $1.66^{\circ}$ & $0.66^{\circ}$ & $1^{\circ}$ \\
20 & $2.33^{\circ}$ & $0.66^{\circ}$ & $1.67^{\circ}$ \\
24 & $0.66^{\circ}$ & $0^{\circ}$ & $0.66^{\circ}$ \\
28 & $2.66^{\circ}$ & $1.66^{\circ}$ & $1^{\circ}$ \\
32 & $1.66^{\circ}$ & 0.66 & $1^{\circ}$ \\
36 & $3.33^{\circ}$ & $2^{\circ}$ & $1.33^{\circ}$ \\
40 & $3^{\circ}$ & $2^{\circ}$ & $1^{\circ}$ \\
\hline
\end{tabular}

\section{Discussão}

Os alongamentos realizados nos posicionamentos decúbito dorsal, semiflexão de joelhos e decúbito lateral mostraram ganhos estatisticamente significantes na flexibilidade muscular dos indivíduos. O alongamento no posicionamento decúbito ventral também mostrou ganho de flexibilidade muscular, porém seu resultado não foi estatisticamente significante.

É consenso na literatura que o músculo iliopsoas é o flexor primário da articulação do quadril (8, 30-32), porém possui outras funções bastante discutidas. Alguns autores consideram-no rotador externo, outros interno; látero-flexor da coluna para lado ipsilateral ou contralateral, lordosante ou cifosante lombar. Um estudo eletromiográfico demonstrou atividade muscular do iliopsoas em todas essas funções contraditórias (6). Por este motivo, foi adotada apenas a extensão do quadril como movimento realizado para alongamento em todos os posicionamentos. O joelho era mantido a $90^{\circ}$, evitando insuficiência passiva do reto femural, potencializando o alongamento do tendão do iliopsoas (7).

Em relação aos diversos posicionamentos para alongamento do músculo iliopsoas, a posição mais citada foi decúbito dorsal $(27,28)$, seguida dos posicionamentos semiflexão de joelhos $(27,29)$ e decúbito ventral (7). Apesar de não terem sido encontrados na literatura pesquisada estudos relacionados com o indivíduo em decúbito lateral, neste estudo foi demonstrado, como efeito imediato do alongamento, o ganho de flexibilidade muscular neste posicionamento. Optou-se pela utilização deste posicionamento na tentativa de isolar a ação do músculo em relação à gravidade. A linha de ação e direção da força de gravidade são sempre verticais, e em decúbito lateral atua de forma uniforme sobre todos os pontos do músculo (33).

O posicionamento semiflexão de joelhos realizado de forma autopassiva mostrou ganhos satisfatórios na flexibilidade muscular, corroborando com outro estudo (27). Estes autores indicaram o autoalongamento como componente de um programa de exercícios domiciliares, o que difere da opinião de outro trabalho que afirma que o músculo iliopsoas não é alongado com eficácia quando realizado de forma autopassiva, uma vez que se contrai para ajudar na estabilização (7). Neste presente estudo pôde-se observar que é possível alongar o iliopsoas com eficácia, mesmo durante sua ação estabilizadora na coluna lombar.

O estudo indica também a posição decúbito dorsal para alongamento de forma autopassiva no mesmo programa de exercícios domiciliares, confirmando o presente estudo (27). Neste estudo, ficou demonstrado 
que o alongamento do músculo iliopsoas neste posicionamento produz, como efeito imediato, um ganho de flexibilidade muscular.

Analisando os efeitos imediatos do alongamento no posicionamento decúbito ventral, foi demonstrado que existe ganho na flexibilidade muscular, porém não foi observada significância estatística. Um estudo relata a associação da rotação medial do quadril e inclinação lateral da coluna para o lado contralateral, à extensão do quadril durante o alongamento (7). Somente a realização da extensão da articulação do quadril é suficiente para alongamento desta musculatura (20). Diante da divergência científica, sugere-se a realização de estudos mais controlados para melhor análise dos efeitos imediatos do alongamento.

Apesar de não ser objetivo deste estudo, foi demonstrado que o músculo iliopsoas tende a ser um músculo lordosante quando encurtado, corroborando com outros estudos $(31,34,35)$.

O presente estudo buscou determinar os efeitos imediatos do alongamento na flexibilidade muscular por meio de uma análise goniométrica. Além de aumentar a amplitude de movimento articular, o alongamento restaura e/ou mantém o comprimento e o número dos sarcômeros em série, sendo de fundamental importância na hipertrofia das fibras musculares e na hiperplasia $(15,23)$. O ajuste no comprimento do sarcômero do músculo auxilia-o no desenvolvimento da tensão máxima, tornando, dessa forma, os exercícios de alongamento uma ferramenta terapêutica frequentemente utilizada na reabilitação física e desportiva $(13,15,16,23)$.

Em relação ao tempo de sustentação e frequência do alongamento, estudos relatam que um número mínimo de repetições é capaz de realizar alterações na unidade músculo-tendão, aumentando a flexibilidade dos tecidos moles $(12,19,36)$. Não há aumento de flexibilidade quando a duração do alongamento é aumentada de 30 a 60 segundos, ou quando a frequência de alongamento é aumentada de uma a três vezes por dia $(18,23)$. Corroborando com outros estudos $(13,14,18,22,23)$, optou-se pela realização de apenas uma única sessão de alongamento estático e sua sustentação por um período de 60 segundos, sendo observada sua eficácia nos alongamentos.

Mesmo sendo considerada instrumento padrão-ouro para avaliação musculoesquelética (24), pelo manuseio fácil, barato e por propiciar que as medidas sejam tomadas rapidamente, a utilização da goniometria como instrumento de coleta de dados foi uma limitação deste estudo (37). A medida de angulação articular que represente a flexibilidade de tecidos moles pode ser influenciada por fatores como fáscias musculares, tensão muscular, tendões, ligamentos e cápsulas, não representando apenas o encurtamento muscular (30, 38).

Foi observado que existem poucas produções científicas relacionadas ao alongamento do músculo iliopsoas, o que restringiu a discussão dos achados. Este estudo vem fornecer mais uma produção bibliográfica sobre o iliopsoas, tendo um importante impacto no meio científico.

Assim como qualquer outro grupo muscular do corpo humano, o músculo iliopsoas se comporta dentro do conceito biomecânico de alongamento. Observa-se que, nas condições em que o fêmur é posicionado no sentido oposto à ação muscular, o alongamento é mais efetivo no que diz respeito à distância entre as inserções (20).

\section{Conclusão}

Neste protocolo realizado, observou-se, como efeito imediato do alongamento na flexibilidade do músculo iliopsoas, um ganho na flexibilidade muscular nos posicionamentos decúbito dorsal, semiflexão de joelhos e decúbito lateral. O músculo iliopsoas pode ser alongado nestes posicionamentos por meio da extensão da articulação coxofemural em uma única sessão de alongamento estático sustentado por 60 segundos. Observou-se, também, tendência à retroversão e neutralização da pelve após realização deste tipo de alongamento. Os diferentes posicionamentos fornecem maior variabilidade de posições, permitindo ao fisioterapeuta escolher qual a mais adequada para cada indivíduo, facilitando a sua práxis.

\section{Referências}

1. Béziers MM, Piret S. A coordenação motora: aspecto mecânico da organização psicomotora do homem. São Paulo: Summus; 1992. 
2. Norris CM. Spinal stabilisation: muscle imbalance and the low back. Physiotherapy. 1995;81(3):127-38.

3. Almeida ICGB, Sá KN, Silva M, Baptista A, Matos MA, Lessa I. Prevalência de dor lombar crônica na população da cidade de Salvador. Rev Bras Ortop. 2008;43(3):96-102.

4. Cox JM. Dor lombar: mecanismo, diagnóstico e tratamento. 6a ed. Barueri: Manole; 2002.

5. Rolf IP. Rolfing: a integração das estruturas humanas. São Paulo: Martins Fontes; 1990.

6. Busquet L. As cadeias musculares dos membros inferiores. Belo Horizonte: Busquet; 2001.

7. Lee D. A cintura pélvica: uma abordagem para o exame e tratamento da região lombar, pélvica e do quadril. Barueri: Manole; 2001.

8. Andersson E, Oddsson L, Grundstrom H, Thorstensson A. The role of the psoas and iliacus muscles for stability and movement of the lumbar spine, pelvis and hip. Scand J Med Sci Sports. 1995;5(1):10-6.

9. Kim HJ, Chung S, Kim S, Shin H, Lee J, Kim S, Song MY. Influences of trunk muscles on lumbar lordosis and sacral angle. Eur Spine J. 2006;15(4):409-14.

10. Harvey L, Herbert R, Crosbie J. Does stretching induce lasting increases in joint ROM? A systematic review. Physiother Res Int. 2002;7(1):1-13.

11. Winters MV, Blake CG, Trost JS, Marcello-Brinker TB, Lowe LM, Garber MB. Passive versus active stretching of hip flexor muscles in subjects with limited hip extension: a randomized clinical trial. Phys Ther. 2004;84(9):800-7.

12. Taylor DC, Dalton JD, Seaber AV, Garrett WE. Viscoelastic properties of muscle-tendon units. The biomechanical effects of stretching. Am J Sports Med. 1990;18(3):300-9.

13. Coutinho EL, Gomes ARS, França CN, Oishi J, Salvini TF. Effect of passive stretching on the immobilized soleus muscle fiber morphology. Braz J Med Biol Res. 2004;37(12):1853-61.

14. Coutinho EL, deLuca C, Salvini TF, Vidal BC. Bouts of passive stretching after immobilization of the rat soleus muscle increase collagen macromolecular organization and muscle fiber area. Connect Tissue Res. 2006;47(5):278-86.

15. Menon T, Casarolli LM, Cunha NB, Souza L, Andrade PHM, Albuquerque CE, et al. Influência do alongamento passivo em três repetições de 30 segundos a cada 48 horas em músculo sóleo imobilizado de ratos. Rev Bras Med Esporte. 2007;13(6):407-10.

16. Carvalho LC, Shimano AC, Picado CHF. Estimulação elétrica neuromuscular e o alongamento passivo manual na recuperação das propriedades mecânicas do músculo gastrocnêmio imobilizado. Acta Ortop Bras. 2008;16(3):161-4.

17. Bertolini GRF, Barbieri CH, Mazzer N. Análise longitudinal de músculos sóleos, de ratos, submetidos a alongamento passivo com uso prévio de ultrassom terapêutico. Rev Bras Med Esporte. 2009;15(2):115-8.

18. Bandy WD, Irion JM, Briggler M. The effect of time and frequency of static stretching on flexibility of the hamstring muscles. Phys Ther. 1997;77(10):1090-6.

19. Roberts JM, Wilson K. Effect of stretching duration on active and passive range of motion in the lower extremity. Br J Sports Med. 1999;33(4):259-63.

20. Barroso TO. Qual melhor posicionamento para se alongar o músculo piriforme? [dissertação]. Salvador: Escola Bahiana de Medicina e Saúde Pública; 2005.

21. O'Sullivan K, Murray E, Sainsbury D. The effect of warm-up, static stretching and dynamic stretching on hamstring flexibility in previously injured subjects. BMC Musculoskelet Disord. 2009;10:37.

22. Gajdosik RL. Passive extensibility of skeletal muscle: review of the literature with clinical implications. Clin Biomech. 2001;16(2):87-101. 
23. Secchi KV, Morais CP, Cimatti PF, Tokars E, Gomes ARS. Efeito do alongamento e do exercício contra-resistido no músculo esquelético de rato. Rev Bras Fisioter. 2008;12(3):228-34.

24. Palmer ML, Epler ME. Fundamentos das técnicas de avaliação músculoesquelética. 2a ed. Rio de Janeiro: Guanabara Koogan; 1998.

25. Bienfait M. Bases elementares: técnicas de terapia manual e osteopática. 2a ed. São Paulo: Summus; 1997.

26. Watson AWS. Procedure for the production of high quality photographs suitable for the recording and evaluation of posture. Rev Fisioter Univ São Paulo. 1998;5(1):20-6.

27. Keskula DR, Lott J, Duncan JB. Snapping iliopsoas tendon in a recreational athlete: a case report. J Athl Train. 1999;34(4):382-5.

28. Mcatee RE. Alongamento facilitado. São Paulo: Manole; 1998.

29. Möller M, Ekstrand J, Öberg B, Gillquist J. Duration of stretching effect on range of motion in lower extremities. Arch Phys Med Rehabil. 1985;66(3):171-3.

30. Kapandji AI. Fisiologia articular: membros inferiores. 5a ed. Rio de Janeiro: Guanabara Koogan; 2000.

31. Hamill J, Knutzen KM. Bases biomecânicas do movimento humano. São Paulo: Manole; 1999.

32. Cutter NC, Kevorkian CG. Provas funcionais musculares. São Paulo: Manole; 2000.

33. Norkin CC, Levangie PK. Articulações: estrutura e função: uma abordagem prática e abrangente. 2a ed. Rio de Janeiro: Revinter; 2001.

34. Kapandji AI. Fisiologia articular: tronco e coluna vertebral. 5a ed. Rio de Janeiro: Guanabara Koogan; 2000.

35. Smith LK, Weiss EL, Lehmkuhl LD. Cinesiologia clínica de Brunnstrom. 5a ed. São Paulo: Manole; 1997.

36. Polizello JC, Carvalho, LC, Freitas FC, Padula N, Shimano A, Mattiello-Sverzut AC. Propriedades mecânicas do músculo gastrocnêmio de ratas, imobilizado e posteriormente submetido a diferentes protocolos de alongamento. Rev Bras Med Esporte. 2009;15(3):195-9.

37. Marques AP. Manual de goniometria. 2a ed. Barueri: Manole; 2003.

38. Harvey D. Assessment of the flexibility of elite athletes using the modified Thomas test. Br J Sports Med. 1998;32:68-70.

Recebido: 04/07/2010

Received: 07/04/2010

Aprovado: 01/09/2010

Approved: 09/01/2010 